\title{
Motion Capture Technology in Sports Science: 3D Virtual Sports Platform with Kinect
}

\author{
Spor Bilimlerinde Hareket Yakalama Teknolojisi: Kinect ile \\ Üç Boyutlu Sanal Spor Platformu
}

\author{
Erman Yükseltürk ${ }^{1}$, Hasan Erbay ${ }^{2}$, Mehmet Kutlu ${ }^{3}$ \\ ${ }^{1}$ Kırıkkale University, Computer Education and Instructional Technology, Kırıkkale, Turkey \\ ${ }^{2}$ Kırıkkale University, Computer Engineering, Kırıkkale, Turkey \\ ${ }^{3}$ İstanbul Gelişim University, School of Physical Education and Sports, İstanbul, Turkey
}

E. Yükseltürk

0000-0003-0690-0010

H. Erbay

0000-0002-5436-3961

M. Kutlu

0000-0003-3441-9929

Geliş Tarihi / Date Received: 08.08.2017

Kabul Tarihi / Date Accepted: 01.10.2017

Yayin Tarihi / Date Published: 29.11.2017

\section{Yazışma Adresi /}

Corresponding Author:

Erman Yükseltürk

Kırıkkale Üniversitesi,

Bilgisayar ve Öğretim

Teknolojileri Eğitimi

Bölümü, Kırıkkale, Turkey

E-mail: eyukselturk@gmail.com

(C2017 Türkiye Spor Hekimleri Derneği. Tüm hakları saklıdır.

\section{ABSTRACT}

Regular sports activity is considered to be beneficial for life quality and health. On the other hand, regular sporting opportunities are not widespread, especially in developing countries. It may be possible to provide an alternative solution for physical activity in the control of a virtual instructor, without being physically in the same place, thanks to the facilities provided by technologies such as Internet and Kinect. In this respect, the three dimensional virtual sports platform Kinect was designed and developed. The different features of the platform are described, and the advantages of new technology achievement and possibilities of alternative sports practice are given.

Key Words: Exercise, virtual platform, technology, internet

\section{öz}

Düzenli spor yapmanın yaşam ve sağlık kalitesi için yararlı olduğu kabul edilmektedir. Fakat düzenli spor yapma olanaklarının özellikle gelişmekte olan ülkelerde yeterince yaygınlaşmadığı gözlenmektedir. İnternet ve Kinect gibi güncel ve gelişmiş teknolojilerin sağladığı olanaklar ile, spor yapamayanlara fiziksel olarak aynı ortamda bulunmaksızın, sanal eğitmen kontrolünde spor yapabilme olanağı sunmanın alternatif bir çözüm yaratabileceği düşünülmektedir. Bu doğrultudaki çalışmalarla, Kinect üç boyutlu sanal spor platformu tasarlanıp geliştirilmiştir. Geliştirilen platformun özellikleri, yeni teknolojilerin avantajlarının kullanıldığı platformlar ile alternatif spor yapma olanakları gözden geçirilmektedir.

Anahtar Sözcükler: Egzersiz, sanal platform, teknoloji, internet

Available at: http://journalofsportsmedicine.org and http://dx.doi.org/10.5152/tjsm.2017.083

Cite this article as: Yükseltürk E, Erbay H, Kutlu M. Motion capture technology in sports science: 3D virtual sports platform with Kinect. Turk J Sports Med. 2017;52:155-62.

\section{GíRIŞ}

İnsan yaşamını sürdürmek için hareket etmektedir. Ancak insan organizmasının uygarlık geliştikçe daha az hareket ettiği gözlenmektedir. Günümüzde teknoloji, insanların hareket etme alışkanlıklarını büyük ölçüde azaltmaktadır. Otomobiller, yürümeye olan gereksinimi aza indirmiș, ağır işleri yerimize yapan makineler günlük hayattaki yerlerini almıştır. Bunun yanı sıra televizyon ve bilgisayar gibi aygitlar, uzun süre hareketsiz kalınmasına neden olmaktadır. Bu olumsuz koşulların getirdiği hareketsiz 
yaşam tarzından kurtulmanın yöntemlerinden biri de düzenli egzersiz yapmaktır.

Araştırmalar, en hareketsiz kişilerin bile, yaşamlarına düzenli olarak kısa yürüyüşler gibi hafif egzersizler kattıklarında, sağlık açısından önemli yararlar kazanabileceğini göstermektedir. Egzersiz yapmanın çok yönlü yararları olduğu kanıtlanmış olsa da, yaşam koşullarının getirdiği olumsuzluklar egzersiz yapmayı zorlaştırmakta, gerek zaman ayırma problemi, gerekse de var olan olanakların kısıtlı olması insanları daha da hareketsiz yaşam tarzına yöneltmektedir (1-4). Bütün bunlara rağmen, son yıllarda gelișen yöntem ve teknolojilerin farklı egzersiz yapma fırsatlarına aracı olabileceği düşünülmektedir. Üç boyutlu hareket algılama sistemleri, çevrimiçi spor salonları, arttırılmış gerçeklik uygulamaları ve video oyunları birer örnek olarak verilebilir (5-7).

\section{Egzersizin İnsan Organizması Üzerindeki Etkileri}

Egzersizin insan organizması üzerindeki etkileri incelendiğinde, her yaş grubunda olumlu yansımaları gözlenmektedir. Bunlardan en yaygın hissedilenin bireylerin düzenli egzersiz sonrasında günlük yaşantı kondisyonlarının artması olduğu bilinmektedir. Bu artış sonuçta, insanın kendisini daha enerjik hissedip tembellikten uzaklaşmasını ve daha az yorularak iş yapmasını sağlamaktadır. Ayrıca hastalık nedeniyle çalışılmayan gün sayısını azaltmakta, organizmayı beden ve ruhsal streslerin yıpratıcı etkisinden korumaktadır. Örnekleri merdiven çıkma, otobüse koşma, hızlı yürüme ve bir yükü kaldırma veya taşıma gibi sayılabilir. Sonuçta kişinin günlük işlerini kolayca yapması ve yorulmadan tamamlaması sağlanmaktadır. Kişinin belirli bir program çerçevesinde fiziksel egzersiz yapmasının ardından, egzersiz öncesi ve sonrasındaki günlük işler karşısındaki dayanıklılığının arttığı gözlemlenmektedir (3,811). Üç boyutlu egzersizin sosyolojik ve psikolojik yararlarından bahsedilirken siralanan bazı maddeler şöyledir (11):

- Hayata daha mutlu bakma,

- Kendine güvenin artması,

- Öz saygının geliştirilmesi,

- Organizmayı bedensel ve ruhsal streslerin yıpratıcı etkilerinden koruma,

- Sinirli ve hiperaktif yapıyı sakinleștirme,
- İnsanlarla çabuk arkadaşlık kurma ve paylaşma, yardımlaşma duygularını geliştirmeye yardımcı olma.

Egzersizin bir diğer olumlu etkisi de tıbbi olanıdır. Örneğin, kas lifi kalınlığının 20-50 mikrondan fazla olması durumunda kas lifleri sayısında çoğalma görülmektedir. \%75-90 arası şiddetle yapılan yüklenmeler kas kuvvetini geliştirir. Bir kasın çapı, yüksek gerilimde uyarılar verilmesiyle artar. Enerji depolarının artması ve kılcal damarların genişlemesi kas dayanıklılığını sağlar. Çabukluk sağlayan uyarılarla kasın kasılma hızı yükseltilir. Egzersiz; kalp ve dolaşım sistemini de etkiler. Egzersiz sırasinda gereksinen kan dokulara ulaştırılır. Kasların daha fazla oksijen alması gerekir ve kalp daha hızlı kan pompalar. Böylece dolaşım sistemi daha düzenli çalışır. Egzersizin solunum sistemine olumlu etkisiyle soluk alma yoğunluğu artar. Yüklenme durumunda soluk alıp vermede ekonomik ortam elde edilir. Çalışma sırasında gereksinen oksijen alınıp verim arttırılır. Kemik ve kas sağlığı desteklenir. Kan basıncı düşürülür ve vücutta oluşan toksinlerin dışarı atılmasına yardımcı olunur (3,8-11). Zorba, egzersizin fizyolojik ve motorik yararlarından bahsederken azalma gözlenen değerlerden bazılarını şöyle sıralamaktadır (11):

- Kalp krizi riskinde veya kalp krizi geçirmiş kişilerin tekrar geçirme riskinde,

- Hipertansiyon riskinde,

- Kanser risklerinde (kolon, prostat, meme, vb.),

- Bel ve sirttaki kaslardan kaynaklanan ağrllarda,

- Kandaki kolesterol düzeyinde,

- Yaşlanma sürecinde,

- Kadınlarda hamilelikten kaynaklanan (sırt ağrıları, vb.) rahatsızlıklarda

Çağın en büyük sağlık sorunlarından biri olan şişmanlığın da önemli nedenlerinden biri fiziksel hareket azlığı olarak bilinmektedir. Gelişmiş pek çok ülkede olduğu gibi Türkiye'de de şişmanlık problemi yaşayanların sayısında artış olduğu gözlenmektedir. Örneğin, Türkiye İstatistik Kurumu (TÜIKK)`nun 2012 yılında yaptığı Türkiye sağlık araştırması sonuçlarına göre 15 ve daha yukarı yaştaki nüfusun \%17.2'sinin obez olduğu belirlenmiştir. Vücut kütle indeks değerleri incelendiğinde, toplumun \%34.8'inin fazla kilolu, \%44.2'sinin normal kilolu, \%3.9'unun ise düşük kilolu olduğu saptanmıștır. Elde edilen veriler cinsiyet açısından değerlendirildiğinde ise 
kadınların \%20.9'unun obez ve \%30.4'ünün fazla kilolu olduğu belirlenmiştir. Erkeklerde ise bu oranlar \%13.7 ve \%39.0 olarak saptanmıştır (12). Düzenli egzersizin çağın önemli rahatsızlıklarından olan şişmanlıktan kurtulmanın bir yolu olduğu açıktır.

\section{Spor Bilimlerinde Teknoloji Kullanımı}

Teknoloji alanındaki hızlı gelişmeler her alanda olduğu gibi spor alanında da etkilerini göstermekte ve kullanılan araç-gereç ve malzemelerden spor salonları ve stadyumlara kadar her unsurun değişim ve gelişimine katkıda bulunmaktadır (13). Bilgisayar teknolojileriyle hızlı bir şekilde verilerin işlenebilmesi ve mültimedya açısından da çok kaliteli düzeye ulaşılmış olması bilişsel öğrenmelerin yanı sıra psikomotor becerilerin öğrenilmesini de sağlamaktadır. Projektör, tepegöz, internet, bilgisayar, video kamera gibi birçok aygit spor alanında etkili olarak kullanılmakta (14), ancak beden hareketlerine duyarlı bir sistem olan Kinect teknolojisi spor bilimlerinde giderek daha önemli bir yere sahip olmaktadır.

Kinect, Microsoft firmasinca 2010 yılında dünya piyasalarına "Project Natal" adı altında satışa sunulmuş güncel bir görüntü algılama sensörüdür. Xbox 360 ve Windows işletim sistemi uyumlu bu sensör, derinlik kamera sensörü, RGB kamera sensörü, dörtlü mikrofon grubu ile üç boyutlu şekilde hareketleri belirtilen aralıklarla yakalama, yüz tanıma ve ses algılama olanağı sunmaktadır. Kinect yazılım geliştirme kitinde bir iskelet, insan vücudunda bulundukları yerlere göre numara verilmiş 24 adet eklemden oluşur ve bu eklemlerin pozisyonları ve uzaklıkları izlenerek vücut hareketlerini görüntüye işler. Kinect teknolojisi ekstra komut denetleyicisine gereksinmeden, vücut hareketlerinin yazılım veya oyun üzerinde kontrol ve etkileşim kurmasına olanak sağlar. $\mathrm{Bu}$ özelliği nedeniyle oyun, tıp, sağlık, vb. alanlarda büyük ilgi görmüștür (15-17), (Şekil 1).

Hareket temelli bir teknoloji olması nedeniyle spor bilimleri alanında bir kaç yıldır Kinect ile ilgili yapılan çalışmaların sayısında artış gözlemlenmektedir. Özellikle, geleneksel spor eğitimlerinden bire bir veya birden fazla kişiyle yüz yüze yapılan eğitimlerde sadece zaman ve mekan sınırlaması değil, aynı zamanda yüksek maliyetleri nedeniyle bazı problemlerle karşılaşılmaktadır. Bu nedenle yüksek oranda doğru veriler veren hareket yakalama aracı olarak Kinect gibi teknolojilerin çözüm olarak kullanılabileceği önerilmektedir (18). Başka bir deyişle, bu yeni hareket izleme teknolojisinin daha güvenilir ve doğru izleme sonuçları sağlayabildiği, aynı zamanda ürün maliyeti ve karmaşıklığının daha az olduğu vurgulanmaktadır (21).

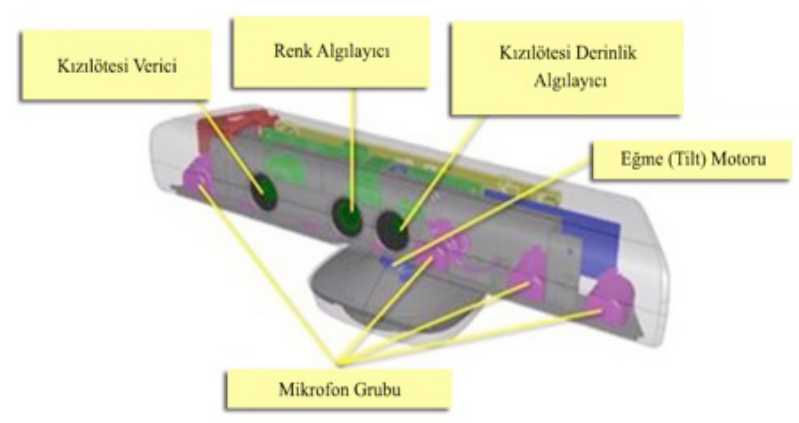

Şekil 1. Kinect cihazının donanım bileşenleri

Literatür incelendiğinde, bu yeni teknolojiye ilişkin araştırmalarda olumlu sonuçların alındığı görülmektedir. Örneğin, daha önceden yaralanma geçirmiş genç erkek sporcuların denge yeteneğinin tekrar kazandırılmasında Xbox Kinect teknolojisi de kullanılmış ve geliştirilen yöntemin değerli, uygulanabilir ve keyifli olduğu belirtilmiștir (19). Başka bir çalışmada, disk atma eğitimi verilirken Kinect teknolojisinden yararlanılarak üç boyutlu hareket yakalama ve geri bildirim sistemi kullanılmıștır. Kullanılan sistem ile öğrenciler kol hareketini sabit yükseklikte tutmak, beli bükmek ve dirseği bel açısına göre uzatmak için eğitilmiştir. Deneysel çalışmanın sonucuna göre, kullanılan sistemin yeni başlayanların hareketlerini iyileştirmede etkili olduğu söylenmektedir (20). Buna ek olarak, badminton sporcularının performans değerlendirmesinin yapıldığı başka bir çalışmada, Kinect hareket izlemi ile saptanan iskelet ivmesi araştırılmış ve kolun bilekten omuza kadar kinematik hareketi gözlenmiştir. Kinect teknolojisi yardımıyla vücut bağlantılarının hızlanmasını doğru ölçülebildiğinin belirtildiği çalışmada, benzer araştırmalarda bu teknolojinin kullanımı önerilmiştir (21). Basketbol öğrenen yeni oyuncuların doğru atışlarını 
sağlamaya yardımcı olması için geliştirilen bir çalışmada da Kinect derinlik sensörü kullanılmış; çalıșma sonuçlarında oyuncuların bu yeni sistem sayesinde gerçek zamanlı geribildirimler aldığı gözlenmiştir (22).

Kinect'in yeni bir teknoloji olmasına rağmen hareket temelli teknolojik eğitim ortamlarının sayısının artacağını söyleyebiliriz. Bu teknolojinin özellikle spor yapılırken güncel teknolojilerden yardım alınan ortamlara verimli şekilde uyarlanabileceğine kuşku yoktur. Burada yazarların danıșmanlığında geliştirilen Kinect ile üç boyutlu sanal bir spor platformunun ana özellikleri paylaşılmaktadır.

\section{Kinect ile Üç Boyutlu (3B) Sanal Spor Platformu}

Kinect ile üç boyutlu sanal spor platformunun kullanılmasının yenilikçi bir yaklaşım olduğu söylenebilir. Ülkemizde ise benzer uygulamalar görülmemektedir. Platformun tasarlanmasına ve geliştirilmesine, analiz çalışmasıyla başlanmıștır. $\mathrm{Bu}$ analiz çalışması sırasında literatür detaylıca taranmış ve özellikle yurt dışında yapılan benzer projeler incelenmiştir (8). Değerlendirmeler sonrasında, yeni bir hareket algılama teknolojisi olan Kinect ve İnternetin yardımıyla, özellikle çeşitli nedenlerle düzenli spor yapamayanlara, sanal eğitmen kontrolünde birlikte spor yapma olanağını sağlayan 3B sanal spor platformu geliştirilmiştir. Platform; Bilgisayar Mühendisliği, Beden Eğitimi ve Spor Bölümü ve Bilgisayar ve Öğretim Teknolojileri Eğitimi Bölümü uzman ve akademisyenleri tarafından tasarlanmıştır (Şekil 2). Platformu benzerlerinden ayıran en temel özellikleri şöyle sıralanabilir:

- Platform dinamik bir yapıya sahiptir, kolayca güncellenebilir ve uyarlanabilir.

- Platformu kullanmak için sadece Kinect ve internete bağlı bir bilgisayar yeterlidir.

- Çok kullanıcılı yapısıyla eğitmen ve katılımcı sayı sinırlamasına gerek yoktur.

- Sunucu üzerindeki veri tabanı desteği ile her türlü hareket, program, katılımcı bilgileri ve programlar kayıt altına alınabilmektedir.

- 3B görsel ve avatarlar (modeller) kullanılarak geliştirilen gerçekçi arayüzleri bulunmaktadır.

Sanal Spor Platformu, 3D Studio Max ve Unity 3D programı ile tasarlanıp masa üstü uygulama olarak çalışabilecek şekilde geliştirilmiştir (Şekil 3) ve internet üzerinden sunucu veri tabanına bağlanabilmektedir. $\mathrm{Bu}$ platform, menüler kullanarak birden fazla kullanıcının giriş yapması için farklı ekranlardan oluşmaktadır. Bir başka deyişle uygulamada eğitmen ve katılımcılar farklı ekran görüntüleri görmektedir.
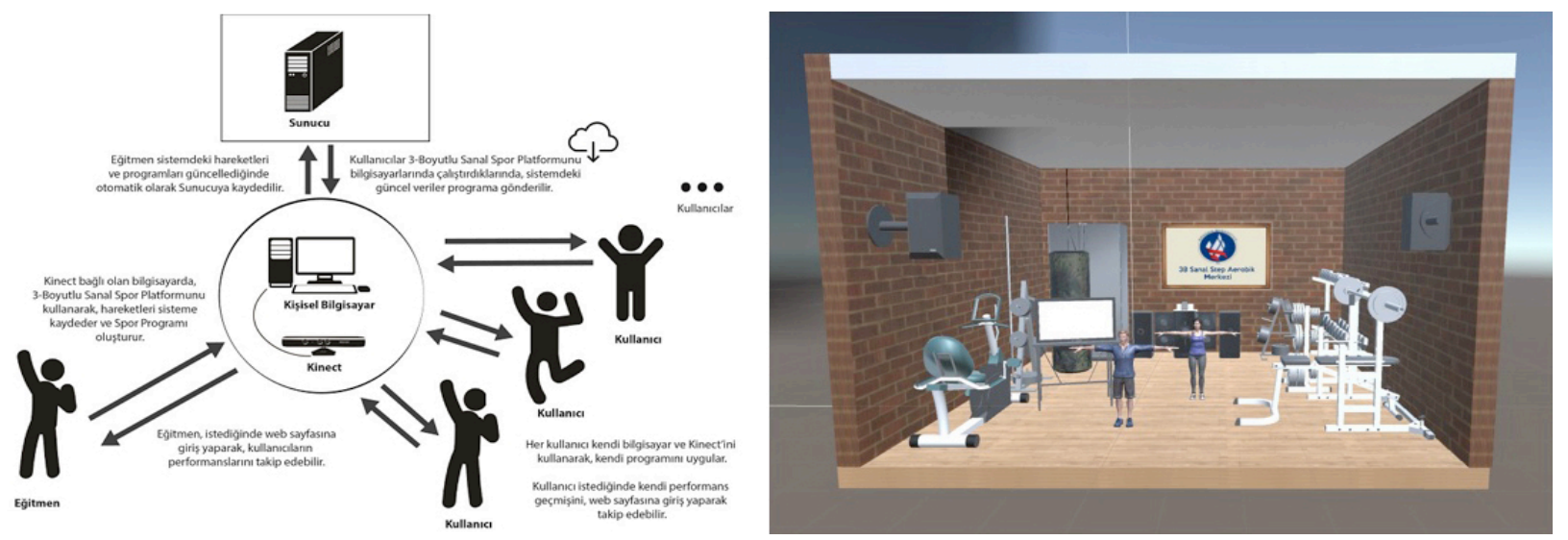

Şekil 2. Kinect ile 3B sanal spor platformu 


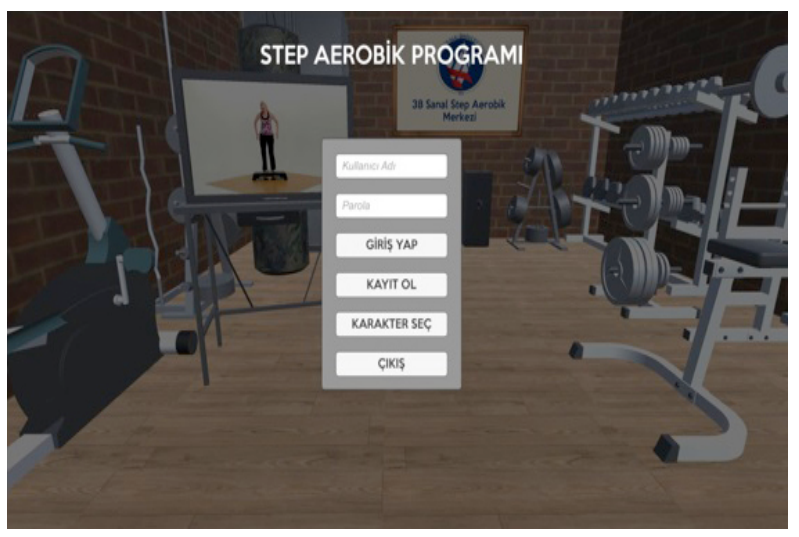

Şekil 3. Platformun giriş ekranı

Eğitmenler, Kinect kamera bağlantılı bilgisayarları kullanarak istedikleri spor hareketlerini kayıt edebilecek (örneğin, sağ kolu sekiz kez kaldırmak gibi) ve kayıt edilen çok sayıdaki hareketleri birleştirerek planladıkları programları (örneğin, aerobik gibi) olușturabilmektedir. Her bir harekete ve programa isimler verilebilmektedir. Katılımcı olarak giriş yapanlar ise eğitmen tarafından oluşturulan programları seçip spor aktivitelerini yapabilmektedir. Hareketlerini yaparken ekranda Kinect kamera sayesinde kullanacakları avatar ve eğitmenin sanal hareketlerini görebilirler. Eğitmenin hareketleriyle eş zamanlı olarak karşılaştırma yapılmakta, yanlış hareket ettirilen vücut bölgeleri ekranda kırmızı olarak görünüp geri bildirim alınmaktadır. Eğitmen ve katılımcı hareketleri Dinamik Zaman Eşleştirme (Dynamic Time Warping, DTW) algoritması ile karşılaştırılır. Burada eğitmenin Kinect kamera kullanarak kayıt ettiği hareketlerin $\mathrm{X}, \mathrm{Y}, \mathrm{Z}$ koordinatları ve açıları zaman da dikkate alınarak katılımcların hareketleriyle kıyaslanır (21). Sonuçlar seçilen spor programı tamamlanınca hareketlerin doğru yapılma yüzdesi ile birlikte ortalama olarak ekranda gösterilir ve veri tabanına ilgili katılımcı performansı olarak kayıt edilir. Şekil 3'te görüldüğü üzere, platforma, "Kullanıcı adı" ve "Parola" ile giriş yapılmaktadır. Ayrıca, "Kayıt ol" seçeneği ile eğitmen veya katılımcl olarak sisteme girebilmek için kayıt olunmalıdır. "Karakter seç" ile platformu kullanırken erkek veya kadın avatar seçimi yapılabilmektedir (Şekil 3).

Platformun eğitmene sunduğu yetkiler ise Şekil 4'te görülmektedir. Eğitmenler, katılımcılardan yapılması istenilen hareketleri kayıt eder ve bu

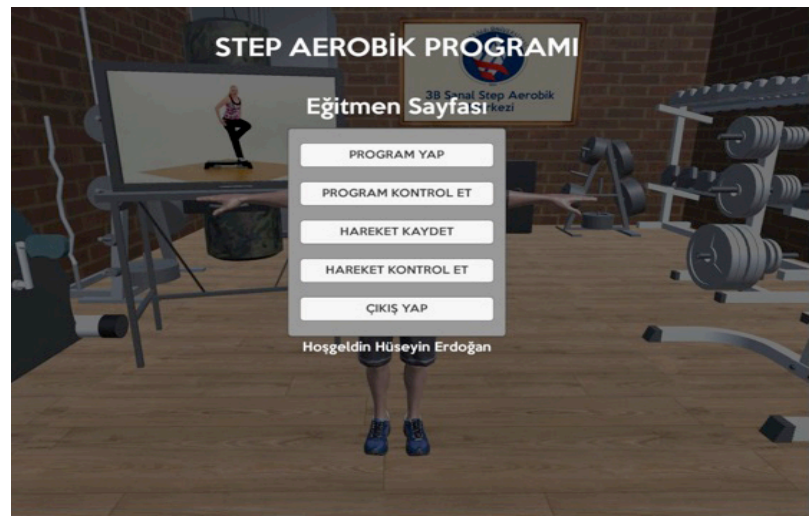

Şekil 4. Platformda eğitmen ekranı

hareketlerden programlar oluşturabilir (Şekil 4). Şekil 5'te eğitmen tarafından hareketlerin kayıt edilmesinden bir ara kesit örneği görülmektedir. Her hareket Kinect bağlı bilgisayar aracılığıyla sisteme kayıt edilmektedir (Şekil 5).

Şekil 6'da, eğitmen tarafından kayıt edilen hareketler seçilerek programlar olușturabilme örneği görülmektedir. Örneğin, "Step programı" isimli program beş hareketten oluşmaktır. Ayrıca, her bir "Hareketin video görüntüsü", "Kaç kez tekrar edileceği"ne ve "Ne kadar sürede hareketin tamamlanacăğ"na da karar verilebilmektedir. Ekranda dört hareket için veri girilmiş, beşinci hareket verileri girilirken ekran görüntüsü alınmıştır. Bunun yanı sıra, katılımcı hareketiyle eğitmen hareketi karşılaştırıldığında doğru hareketin hangi aralıkta yapılabileceği ve toplam program performansının hesaplanacağına dair veriler de bu ekrandan girilebilir (Şekil 6).

Şekil 7'de katılımcının eğitmenin hazırladığı programlardan birini seçip başlattığı ekran görüntüsü paylaşılmaktadır. Ekrandaki avatar, Kinect kamerası yardımıyla katılımcı tarafından hareket ettirilmektedir. Avatarın arkasındaki ekranda eğitmenin hareket dizinini nasıl yaptığı gösterilmektedir. Katılımcı bu videolara göre hareketlerini yapabilmektedir. Her bir hareketin eğitmenin hareketiyle karşılaștırmaları, XYZ düzlemindeki verileri ve hareketin doğruluk oranı sol tarafta görülmektedir (Şekil 7).

Platformda gözüken üç boyutlu avatarlar "Adobe Fuse" programı kullanılarak tasarlanmıștır. Her avatarın iskelet yapısı özel olarak çizilmiş ve avatarın içine giydirilmiştir. Her iki cins için 
tasarlanan avatarlar spor aktivitelerine katılırken katılımcı ve eğitmen tarafından tercih edilirler. $\mathrm{Bu}$ avatarların en büyük özelliği Kinect kamera ile bağlantı kurularak modelin 24 noktasının $\mathrm{X}, \mathrm{Y}, \mathrm{Z}$ koordinatlarının alınabilmesidir. Böylelikle avatarlar programlanabilir ve hareket ettirebilir hale gelmektedir.

Çalışma sürecinde geliştirilen platformun indirilip kurulmasını sağlamak için internette web sayfası

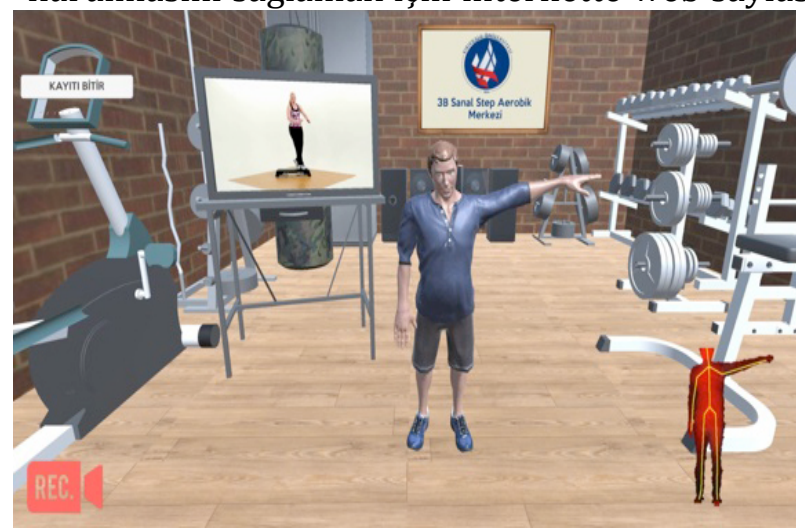

Şekil 5. Hareket kayıt ekranı

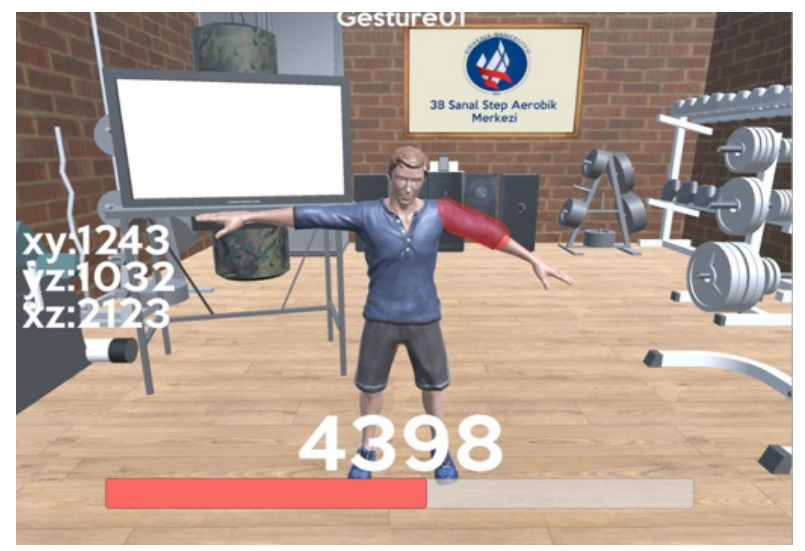

Şekil 7. Katılımcı görüntüsü

\section{Sonuç}

Uzayan yaşamın sağlıklı ve mutlu şekilde sürdürülmesi, düzenli egzersizin bir yaşam tarzı haline getirilmesi ile mümkündür. Fakat, modern yaşamın her geçen gün daha çok benimsenmesi hareketsiz bir yaşam tarzının yaygınlaşmasına neden olmaktadır. Hareketsiz yaşam, kişileri günlük aktivitelerinde dahi zorlanır hale getirmekte ve pek çok hastalığın başlangıcı hazırlanmıștır. Web sitesine "Eğitmen" olarak giriş yapıldığında bütün katılımcıların bilgileri ve platformu kullanıp takip ettiği programlardaki performanslarına erişim sağlanabilmektedir. "Katılımcı" olarak giriş yapıldığında ise bireysel performanslar görülebilmektedir. Böylelikle, üç boyutlu sanal spor platformunu kullananlar spor aktivitelerinin raporlarına internet ortaminda erişebilmektedir (Şekil 8).

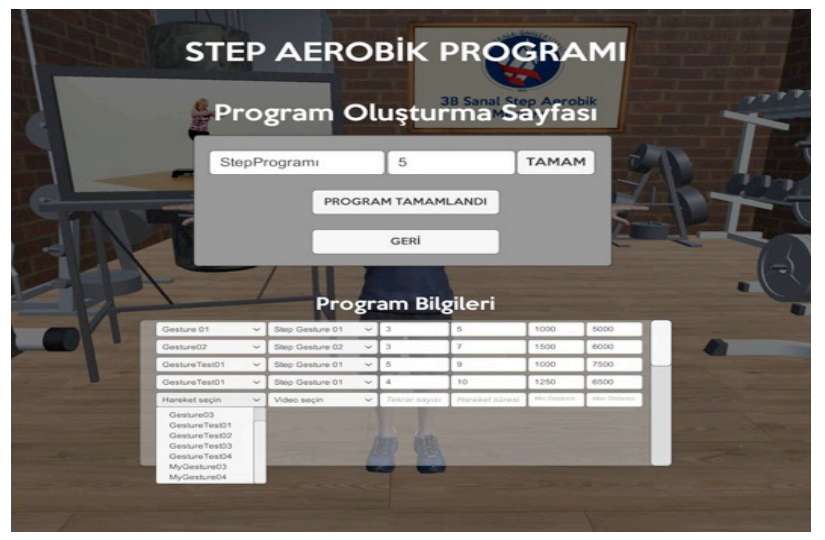

Şekil 6. Program oluşturma

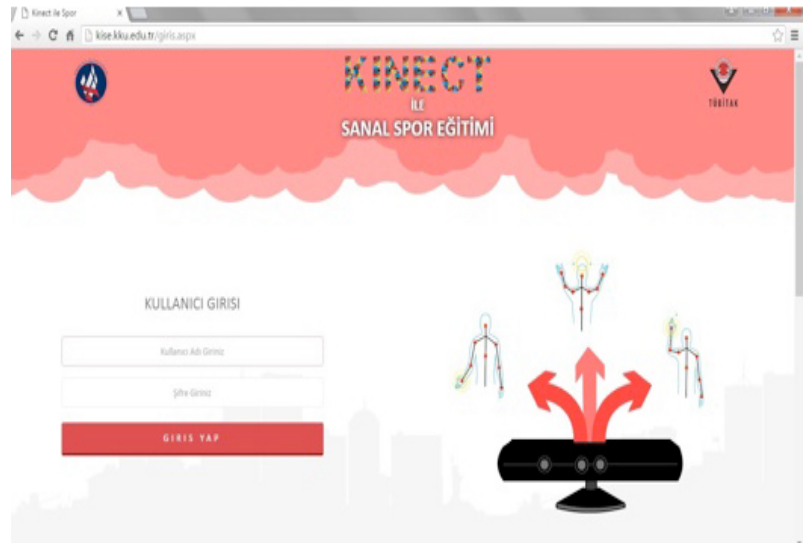

Şekil 8. Platformun web sayfası

olmaktadır. Araștırmalar fiziksel aktivite ve sağlık arasındaki pozitif ilişkiyi ortaya koymasına karşın, insanların yeteri kadar egzersiz yapmadığ belirtilmektedir (23-25). Tüm dünyada bedensel hareket azlığl, gittikçe artan bir biçimde toplumların sağlığını tehdit etmektedir. $\mathrm{Bu}$ nedenle, kişilerin spor yapma olanaklarını arttırmak ve spor alışkanlığını kazandırmaya yardımcı olmak için alternatif yöntemlerin sunulması büyük önem taşımaktadır. Bu konudaki 
eksikleri gidermek ve yeni yöntemler üretmek için güncel ve gelişmiş teknolojilerin avantajlarını kullanmak iyi bir çözüm olabilir. Bu çalışmada olduğu gibi İnternet ve Kinect gibi güncel ve gelişmiş teknolojilerin sağladığı olanaklar ile spor yapma olanağı bulamayanlara fiziksel olarak aynı ortamda olmaksızın, eğitmen kontrolünde spor yapabilme olanağı sunmak alternatif bir çözüm olarak katkı sağlayacaktır.

Kinect üç boyutlu sanal spor platformu ile daha çok kişi eş-zamanlı olarak eğitmen kontrolünde egzersiz programlarını takip edebilecektir. Ayrıca, bu sistemi kullananların katıldığı fiziksel aktiviteler sırasında yaptıkları bütün hareketler kayıt altına alınabilecektir. Böylelikle, fiziksel aktivitelere katılanların kişisel ya da grup performansları incelenebilecek, platform çevrimiçi olacağından geribildirimler eğitmenler tarafından hem anında verilebilecek hem de toplu olarak aktivite sonunda rapor edilebilecektir. Getireceği bu tür yeniliklerle spor bilimleri alanında akademik olarak da kullanılabilecektir.

\section{Öneriler}

Kinect ile üç boyutlu sanal spor platformu son teknolojiler kullanılarak geliştirilmiştir. Bundan sonraki çalışmalarda sistem üzerinden yapılacak spor etkinliklerinin etkisinin incelenmesi planlanmaktadır. Farklı eğitmenlerin hareket ve spor programları kayıt edilerek, farklı katılımcıların kullanımına sunulması düşünülmektedir. Şu anda test aşamalarını sorunsuz geçiren ve herhangi bir problemle karşılaşılmayan sistemi farklı özelliklerdeki kişilerin (örneğin, ev hanımı, yaşlı bireyler gibi) farklı sürelerde (örneğin bir ya da üç ay gibi) kullanması, ardından görüşlerinin alınması ve performanslarının incelenmesi önerilmektedir. Sistemi kullanacak eğitmen ve katılımcılara kullanım öncesi kısa bir eğitim verilmesi, bunun için gerekli açılkamaları içeren broşürlerin ve kullanım videolarının hazırlanması planlanmaktadır.

Sistemin teknik olarak geliştirilmesi için bazı öneriler yapılabilir. Şu anda tek Kinect kullanılmaktadır. Katılımcı hareketlerini algılamak için birden fazla Kinect kullanarak veriler analiz edilebilir, böylelikle farklı algoritmalarla katılımcların performansları daha detaylı incelenebilir. $\mathrm{Bu}$ sistemde sesli komut verme özelliği kullanılmamıştır, sonraki çalışmalarda bu özellik de kullanılarak sisteme uyarlanabilir.

Teşekkür: $\mathrm{Bu}$ çalışma, TÜBITTAK-SOBAG 115K068 nolu proje tarafından desteklenmektedir.

\section{KAYNAKLAR}

1. Buckworth J, Nigg C. Physical activity, exercise, and sedentary behavior in college students. J Am Coll Health. 2004;53:28-34.

2. Çolakoğlu FF. 8 Haftalık koş yürü egzersizinin sedanter orta yaşlı obez bayanlarda fizyolojik, motorik ve somatotip değerleri üzerine etkisi. GÜ Gazi Eğitim Fakültesi Dergisi. 2003;23:275-90.

3. Çolakoğlu FF, Karacan S. Genç bayanlar ile orta yaş bayanlarda aerobik egzersizin bazı fizyolojik parametrelere etkisi. Kastamonu Üniversitesi Kastamonu Eğitim Dergisi. 2006;14:277-84.

4. Nelson MC, Gordon-Larsen P. Physical activity and sedentary behavior patterns are associated with selected adolescent health risk behaviors. Pediatrics. 2006;117(4):1281-90.

5. Cassola F, Morgado L, de Carvalho F, et al. Online-Gym: a 3D virtual gymnasium using Kinect interaction. Procedia Technology. 2014;13:130-8.

6. Zhier L. Research on the physical education teaching system based on 3D human motion capture. International Journal of Signal Processing, Image Processing and Pattern Recognition. 2016;9(12):61-70.

7. Sieluzycki C, Kaczmarczyk P, Sobecki J, et al. Microsoft Kinect as a tool to support training in professional sports: augmented reality application to Tachi-Waza techniques in judo. In: Johnson H, Bródka P, Alhajj R, Eds. ENIC 2016. Proceedings of the Third European Network Intelligence Conference; 2016 Sep 5-7, Wrocław, Poland.

8. Demir M, Filiz K. Spor egzersizlerinin organizma üzerine etkisi. Gazi Üniversitesi Kırșehir Eğitim Fakültesi Dergisi. 2004;5(2):109-14.

9. Penedo FJ, Dahn JR. Exercise and well-being: A review of mental and physical health benefits associated with physical activity. Curr Opin Psychiatry. 2005;18(2):189-93.

10. Warburton DE, Nicol CW, Bredin, SS. Health benefits of physical activity: the evidence. CMAJ. 2006;174(6): 801-9.

11. Zorba E. Herkes için Spor ve Fiziksel Uygunluk. Ankara: Neyir Matbaası; 1999.

12. TÜİK. Sağlık Araştırması 2012. Ankara: Türkiye İstatistik Kurumu; 2012.

13. Devecioğlu S, Altıngül 0 . Spor teknolojilerinde inovasyon. In: Varol A, Varol Y, Çelik V, editörler. IATS'11. Proceedings of the $6^{\text {th }}$ International Advanced 
Technologies Symposium. 2011 May 16-18; Elazı̆̆, Turkey. Elazığ: Fırat Üniversitesi; 2011. p. 46-9.

14. Yaman Ç. Beden eğitimi öğretmenlerinin eğitim teknolojileri ve multimedya kullanım becerileri. Sosyal Bilimler Araştırmaları Dergisi. 2007;2:291-313.

15. Lien CL, Huang CY, Wang CY, et al. Using Kinect to track learning behavior of students in the classroom as video portfolio to enhance reflection learning. In: Biswas G, Wong L, Hirashima T, editörler. ICCE 2012. Proceedings of the 20th International Conference on Computers in Education. 2012 Nov 26-30; Singapore: National Institute of Education; 2012. p. 714-21.

16. Marques L, Siqueira ES, Barros ES, et al. A game for teaching children with disability in reading and writing in Portuguese using voice recognition and Kinect sensor. In: Teichrieb V, Clua LR, Eds. SBGAMES 2011. Proceedings of the 10th Brazilian Symposium on Computer Games and Digital Entertainment. 2011 Nov 7-9, Salvador, Brazil. Federal University of Sao Carlos, Study Laboratory of Human Behavior; 2011.

17. Tenekeci ME, Gümüşçü $A, A$ ğırman, Ö. Harf eğitimi için interaktif Kinect uygulaması. Akademik Bilişim. 1-4 Şubat 2014; Mersin, Türkiye.

18. Che YL, Lu JZ. The key technology research of Kinect application in sport training. Advanced Materials Research. 2014;945-949:1890-3.

19. Vernadakis N, Derri V, Tsitskari E, et al. The effect of Xbox Kinect intervention on balance ability for previously injured young competitive male athletes: a preliminary study. Phys Ther Sport. 2013;15(3):148-55.

20. Yamaoka K, Ueharab M, Shima T, et al. Feedback of flying disc throw with Kinect and its evaluation. Procedia Computer Science. 2013;22:912-20.

21. Taha Z, Hassan MSS, Yap HJ, et al. Preliminary investigation of an innovative digital motion analysis device for badminton athlete performance evaluation. Procedia Engineering. 2016;147:461-5.

22. Bittar É, Desprez P-É, Grisonnet B, et al.: LeBonGeste: Basketball training by entertaining. Procedia Computer Science. 2017;112:1281-7.

23. Müller M. Information Retrieval for Music and Motion. Heidelberg: Springer; 2007.

24. Aydın AD. Türkiye'de sporun topluma yaygınlaştırılması sürecinde yaz spor okullarının rolünün belirlenmesi. Atatürk Beden Eğitimi ve Spor Bilimleri Dergisi. 2008;10:3-11.

25. Sunay H. Türk spor politikasına analitik bir bakış. Spormetre Beden Eğitimi ve Spor Bilimleri Dergisi. 2003; 1:39-42. 